\title{
Retraction Note: Modeling and analysis of environmental vulnerability based on partial differential equation
}

\author{
Liang Song ${ }^{1} \cdot$ Shaodong Chen ${ }^{1} \cdot$ Guoxin Wang ${ }^{1}$
}

Published online: 6 December 2021

C) Saudi Society for Geosciences 2021

Retraction Note: Arabian Journal of Geosciences (2021) 14: 963

https://doi.org/10.1007/s12517-021-07251-8

The Editor-in-Chief and the Publisher have retracted this article because the content of this article is nonsensical. The peer review process was not carried out in accordance with the Publisher's peer review policy. The authors have not responded to correspondence regarding this retraction.

The original article can be found online at https://doi.org/10.1007/ s12517-021-07251-8.

Liang Song

nit_songliang@163.com

Shaodong Chen

zixcan1001@163.com

Guoxin Wang

yuxinwang617@126.com

1 School of Mathematics and Physics, Nanyang Institute of Technology, Nanyang 473004, China 